\title{
Reelin cells and sex-dependent synaptopathology in autism following postnatal immune activation
}

\author{
Maryam Ardalan ${ }^{1}$, Tetyana Chumak ${ }^{2}$, Alexandra Quist ${ }^{1}$, Eva Hermans ${ }^{3}$, Ali H.Rafati ${ }^{4}$, \\ Giacomo Gravina $^{1}$, Seyedeh Marziyeh Jabbari Shiadeh ${ }^{5}$, Pernilla Svedin ${ }^{1}$, Setareh Alabaf ${ }^{1}$, \\ Brian Hansen ${ }^{5}$, Gregers Wegener ${ }^{4}$, Lars Westberg ${ }^{1}$, and Carina Mallard ${ }^{1}$ \\ ${ }^{1}$ Institute of Neuroscience and Physiology, Sahlgrenska Academy at University of \\ Gothenburg \\ ${ }^{2}$ University of Gothenburg \\ ${ }^{3}$ Utrecht University \\ ${ }^{4}$ Translational Neuropsychiatry Unit \\ $5^{\circ}$ Arhus Universitetshospital
}

July 14, 2021

\begin{abstract}
Autism Spectrum Disorders (ASD) are heterogeneous neurodevelopmental disorders with considerably increased risk in male infants born preterm and with neonatal infection. Here we investigated the role of postnatal immune activation on hippocampal synaptopathology by targeting Reelin+ cells in mice with ASD-like behavior. C57/Bl6 mouse pups of both sexes received lipopolysaccharide (LPS, $1 \mathrm{mg} / \mathrm{kg}$ ) on postnatal day (P) 5. At P45, animal behavior was examined by marble burying and sociability test, followed by ex-vivo brain MRI diffusion kurtosis imaging (DKI). Hippocampal synaptogenesis, number and morphology of Reelin + cells, and mRNA expression of trans-synaptic genes, including neurexin-3, neuroligin-1, and cell-adhesion molecule nectin-1 were analyzed at P12 and P45. Social withdrawal and increased stereotypic activities in males were related to increased mean diffusivity on MRI-DKI and overgrowth in hippocampus together with retention of long-thin immature synapses on apical dendrites, decreased volume and number of Reelin+ cells as well as reduced expression of trans-synaptic and cell-adhesion molecules. The study provides new insights into sex-dependent mechanisms that may underlie ASD-like behavior in males following PIA. We identify GABAergic interneurons as core components of dysmaturation of excitatory synapses in the hippocampus following postnatal infection and provide cellular and molecular substrates for the MRI findings with translational value.
\end{abstract}

\section{Hosted file}

LPS MS 21-06-16_combined.pdf available at https://authorea.com/users/375460/articles/530408reelin-cells-and-sex-dependent-synaptopathology-in-autism-following-postnatal-immuneactivation 